\title{
BƯớC ĐÀU ĐÁNH GIÁ HIỂU QUẢ CAN THIỆP BẰNG TẬP ĐỐI KHÁNG Ở BỆNH NHÂN ĐÁI THÁO ĐƯờnG TÍP 2 CÓ MẤT CƠ TẠI BỆNH VIỆN XANH PÔN
}

DOI: 10.47122/vjde.2020.44.2

Nguyễn Thị Thúy Hằng

Bệnh viện Xanh Pôn, Hà Nội

\section{TÓM TẮT}

Qua nghiên cứu 56 bệnh nhân ĐTĐ typ 2 bao gồm $(53,6 \%$ tiền mất cơ, $33,9 \%$ mất cơ vừa và $12,9 \%$ mất cơ nặng) độ tuổi trung bình $64,8 \pm 2,9$ tuổi tham gia tập luyện trong 12 tháng tại nhà, tái khám định kỳ, chúng tôi thu được kết quả như sau: Cải thiện về $\mathrm{ASMI}_{\mathrm{H}}$ ở nhóm tiền mất cơ, mất cơ vừa và mất cơ nặng lần lượt trước và sau tập là $\left(5,46 \pm 0,76 \mathrm{~kg} / \mathrm{m}^{2} ; 5,57\right.$ $\left.\pm 0,73 \mathrm{~kg} / \mathrm{m}^{2}\right), \mathrm{p}<0,01 ;\left(5,31 \pm 0,70 \mathrm{~kg} / \mathrm{m}^{2} ; 5,40\right.$ $\left.\pm 0,65 \mathrm{~kg} / \mathrm{m}^{2}\right), \mathrm{p}>0,05 ;\left(4,68 \pm 0,98 \mathrm{~kg} / \mathrm{m}^{2} ; 4,78\right.$ $\left.\pm 0,98 \mathrm{~kg} / \mathrm{m}^{2}\right), \mathrm{p}>0,05$. Tốc độ đi bộ ở giới nam $0,72 \pm 0,18 \mathrm{~m} / \mathrm{s}$ và $0,82 \pm 0,18 \mathrm{~m} / \mathrm{s}$, ở nữ là 0,62 $\pm 0,14 \mathrm{~m} / \mathrm{s}$ và $0,69 \pm 0,17 \mathrm{~m} / \mathrm{s}$ với $\mathrm{p}<0,05$. Cơ lực tay giới nam là $30,6 \pm 11,0 \mathrm{~kg}$ và $34,4 \pm 12,5$ $\mathrm{kg}$; ở nữ là $14,1 \pm 11,7 \mathrm{~kg}$ và $17,5 \pm 104,5 \mathrm{~kg}$ với $\mathrm{p}<0,05$. Không có sự thay đổi có ý nghĩa thống kê về cân nặng, BMI. Tuy nhiên, huyết áp, mỡ máu, glucose có giảm có ý nghĩa thống kê. Kết luận: Bài tập đối kháng làm tăng khối cơ ở bệnh nhân ĐTĐ typ 2 tiền mất cơ với $\mathrm{p}<0,05$.

\section{ABSTRACT \\ Initially evaluate the effectiveness of resistance training in type 2 diabetes patients with sarcopenia in Saint Paul Hospital \\ Nguyen Thi Thuy Hang Saint Paul hospital, Hanoi}

We selected 56 patients aged 60-70, mean age $64,8 \pm 2,9$, voluntarily participated in the research with diagnosis of pre- sarcopernia and sarcopernia (pre-sarcopernia: 53.6\%, loss sarcopernia: $34.7 \%$, severe muscle loss: $12.5 \%$ ) for intervention by resistance training. The patients did resistance trainning at home, reexaminated every 3 months. Follow - up 12 months training session, the results are: The improvement in $\mathrm{ASMI}_{\mathrm{H}}$ in the pre- sarcopenia, moderate sarcopenia and heavy sarcopenia group before and after training respectively $\left(5.46 \pm 0.76 \mathrm{~kg} / \mathrm{m}^{2} ; 5.57 \pm 0.73 \mathrm{~kg} / \mathrm{m}^{2}\right), \mathrm{p}<$ $0.01 ;\left(5.31 \pm 0.70 \mathrm{~kg} / \mathrm{m}^{2} ; 5.40 \pm 0.65 \mathrm{~kg} / \mathrm{m}^{2}\right)$, $\mathrm{p}>0.05 ;(4.68 \pm 0.98 \mathrm{~kg} / \mathrm{m} 2 ; 4.78 \pm 0.98 \mathrm{~kg} /$ $\left.\mathrm{m}^{2}\right), \mathrm{p}>0.05$. Walking speed for men $0.72 \pm$ $0.18 \mathrm{~m} / \mathrm{s}$ and $0,82 \pm 0.18 \mathrm{~m} / \mathrm{s}$, for women it was $0.62 \pm 0.14 \mathrm{~m} / \mathrm{s}$ and $0.69 \pm 0.17 \mathrm{~m} / \mathrm{s}$ with $\mathrm{p}<0.05$. The man arm muscle force was $30.6 \pm$ $11.0 \mathrm{~kg}$ and $34.4 \pm 12.5 \mathrm{~kg}$; in women it was $14.1 \pm 11.7 \mathrm{~kg}$ and $17.5 \pm 104.5 \mathrm{~kg}$ with $\mathrm{p}<0.05$. There is no change in weigth, BMI, but decrease blood pressure, glucose, Hbalc, lipid profile $(p<0,005)$. Follow-up after 12-month training session on 56 diabetic patients type 2 including 30 pre- sarcopenia patients, 19 patients with moderate sarcopenia and 7 patients with severe sarcopenia improved in post-exercise muscle mass index increased more than before. However, only the pre-muscle loss group was statistically significant different with $\mathrm{p}<0.05$. Conclusion: Resistance training is effective for eliciting gains in lean body mass among type 2 diabetes mellitus with pre sacropenia.

Key word: Resisstance training, typ 2 diabetes mellitus, sacropenia. Hằng

Chịu trách nhiệm chính: Nguyễn Thị Thúy

Ngày nhận bài: 19/10/2020

Ngày phản biện khoa học: 08/12/2020

Ngày duyệt bài: 29/01/2021

Email: ntthangxp@gmail.com

Điện thoại: 0983555506

\section{1. ĐĂT VẤN ĐỀ}

Trong những năm gần đây, mất cơ được chú ý nhiều hơn bởi sự phổ biến và mức độ ảnh hưởng đến sức khỏe của cộng đồng. Mất cơ được mô tả là sự giảm khối lượng và chức năng của cơ liên quan đến tuổi [1]. Mặc dù mất cơ được coi là quá trình sinh lý liên quan tới già hóa, tuy nhiên có nhiều yếu tố làm gia tăng quá trình này như bệnh mạn tính, lối sống tĩnh tại, 
tình trạng dinh dưỡng...ĐTĐ typ 2 làm thúc đẩy quá trình mất cơ sớm hơn, nhanh hơn, làm gia tăng nguy cơ nhập viện, ngã, tàn tật, các biến chứng tim mạch và tử vong [2],[3]. Trong khi đó, Việt Nam là một trong số những quốc gia có tốc độ gia tăng nhanh nhất số bệnh nhân ĐTĐ nên cần phải phát hiện sớm, điều trị kịp thời các biến chứng của ĐTĐ typ 2 trong có mất cơ, giúp giảm gánh nặng về kinh tế và chăm sóc y tế cho xã hội và người bệnh. Cho tới nay, tập luyện đối kháng là phương pháp mang lại hiệu quả cho điều trị mất cơ

Ở Việt Nam, một số tác giả cũng đã nghiên cứu về mất cơ ở bệnh nhân ĐTĐ típ 2 . Tuy nhiên, nghiên cứu về tập đối kháng ở bệnh nhân ĐTĐ típ 2 còn chưa nhiều. Vì vậy, chúng tôi tiến hành nghiên cứu đề tài "Bước đầu đánh giá hiệu quả can thiệp bằng tập đối kháng ở bệnh nhân đái tháo đường típ 2 có mất co" nhằm mục tiêu: Đánh giá hiệu quả can thiệp bằng tập đối kháng ở bệnh nhân đái tháo đường típ 2 có mất co.

\section{2. ĐỐI TƯợNG VÀ PHƯƠNG PHÁP NGHIÊN CÚU}

2.1. Đối tượng nghiên cứu: Là bệnh nhân được chẩn đoán là ĐTĐ típ 2 có kèm theo tiền mất cơ và mất cơ theo tiêu chuẩn chẩn đoán của ADA 2014 và Hiệp hội mất cơ (AWGS) 2014

\subsubsection{Tiêu chuẩn lụ̂a chọn nhóm bệnh} nhân nghiên cúu

Là những bệnh nhân được chẩn đoán ĐTĐ típ 2 theo tiêu chuẩn ADA năm 2014 được điều trị ngoại trú tại Bệnh viện đa khoa Xanh pôn.

\subsubsection{Tiêu chuẩn loại trù̀}

- Bệnh nhân đang có biến chứng cấp tính của ĐTĐ như nhiễm toan ceton, tăng áp lực thẩm thấu, nhiễm trùng.

- Các bệnh nội tiết và một số bệnh gây rối loạn chuyển hóa glucose

- Bệnh nhân đã được phát hiện có khối u như: buồng trứng, $\mathrm{u}$ xơ tử cung, buồng trứng đa nang hoặc ung thư xương, thoái hóa khớp gối nặng

2.2. Phương pháp nghiên cứu

2.2.1. Thiết kế nghiên cúu

- Chọn mẫu thuận tiện, bao gồm 98 bệnh nhân nghiên cứu can thiệp so sánh trước sau với thời gian theo dõi là 12 tháng.

2.2.2.Thời gian và địa điểm nghiên cúu: từ tháng 4 năm 2016 đến tháng 12 năm 2018 tại khoa Khám bệnh, bệnh viện Xanh Pôn.

2.2.3. Quy trình nghiên cúu: Bệnh nhân khám và làm các xét nghiệm tại khoa khám bệnh bệnh viện Xanh pôn, được theo dõi qua các bước sau và được tập theo bài tập của trường Havard Mỹ (2014).

* Bước 1: Lựa chọn bệnh nhân theo tiêu chuẩn được chẩn đoán mất cơ và tiền mất cơ

* Bước 2: Tiếp nhận đánh giá đưa bệnh nhân vào nghiên cứu

Hướng dẫn và giải thích lợi ích và nguy cơ, ký chấp thuận tham gia nghiền cứu.

Hướng dẫn tại Khoa phục hồi chức năng Bệnh viện đa khoa Xanh Pôn và được tư vấn về dinh dưỡng.

* Bước 3: Kê đơn thuốc ngoại trú và lịch trình tập cho từng bệnh nhân

+ Tần số tập: tối thiểu 3-5 lần/tuần.

+ Thời gian tập luyện: 45 - 60 phút bao gồm 3 giai đoạn (khởi động 3- 5 phút, thả lỏng 3 - 5 phút và thời gian còn lại là tập luyện).

+ Cường độ tập luyện: Bài tập mẫu mỗi động tác có 3 chu kỳ, một chu kỳ từ 8 - 15 lần, yêu cầu tập được từ $1-3$ chu kỳ. giữa các chu kỳ có khoảng nghỉ ngắn 10 - 20 giây và giữa các động tác có khoảng nghỉ ngắn 30 giây.

- Hẹn tái khám tại bệnh viện hàng tháng.

* Bước 4: Theo dõi định kỳ hàng tháng trong 3 tháng.

* Bước 5: Đánh giá BN sau 12 tháng nghiên cứu

Khối cơ được đo bằng DEXA sau 12 tháng.

Sau 12 tháng, chỉ có 56 bệnh nhân là đạt được các yêu cầu của nghiên cứu.

\subsubsection{Các biến số nghiên cúu}

Lâm sàng: Các thông tin chung: năm sinh, giới tính, địa chỉ, nghề nghiệp, chiều cao, cân nặng, tình trạng hôn nhân, tình trạng dinh dưỡng.

Khám lâm sàng: chiều cao, cân nặng: BMI, vòng eo, huyết áp và khám lâm sàng một cách toàn diện và kỹ lưỡng tại Khoa khám bệnh Bệnh viện đa khoa Xanh pôn.

Xét nghiệm: Glucose máu lúc đói (máu tĩnh mạch), HbA1C, Lipid máu (CT, TG, HDL-C, 
LDL-C )

Xác định tình trạng mất co:

Đo cơ lục tay: Đo bằng máy áp lực kế cầm tay Jamar $5030 \mathrm{~J} 1$ đo sức nắm của từng tay. Đánh giá cơ lực tay thấp khi nam $<26 \mathrm{~kg}$, nữ $<18 \mathrm{~kg}$.

Đo tốc độ đi bộ: Tốc độ đi bộ được coi là thời gian đi bộ trong $6 \mathrm{~m}$ được đo bằng đồng hồ bấm giây. Đánh giá: Tốc độ đi bộ giảm khi <0,8 m/s.

Đo khối co: Bệnh nhân được đo bằng máy Hologic Explorer $(\mathrm{Mỹ}), \mathrm{ASMI}_{\mathrm{H}}=$ khối cơ tứ chi/(chiều cao) ${ }^{2}$. Khối cơ giảm khi: nam < $7,0 \mathrm{~kg} / \mathrm{m}^{2}$, nữ $<5,4 \mathrm{~kg} / \mathrm{m}^{2}$.

Bảng 2.1. Chuẩn đoán theo hiệp hội mất cơ Châu Á [4]

\begin{tabular}{|c|c|c|c|c|}
\hline \multirow{2}{*}{$\begin{array}{c}\text { Tiêu } \\
\text { chuẩn }\end{array}$} & \multirow{2}{*}{$\begin{array}{l}\text { Phương } \\
\text { pháp đo }\end{array}$} & \multirow{2}{*}{ Phương tiện } & \multicolumn{2}{|c|}{ Giá trị } \\
\hline & & & Nam & Nữ \\
\hline \multirow[t]{2}{*}{1} & \multirow{2}{*}{ Khối cơ } & Hấp thu tia X năng lượng kép; DXA & $7 \mathrm{~kg} / \mathrm{m}^{2}$ & $5,4 \mathrm{~kg} / \mathrm{m}^{2}$ \\
\hline & & Điện trở kháng sinh học(BIA) & $7 \mathrm{~kg} / \mathrm{m}^{2}$ & $5,7 \mathrm{~kg} / \mathrm{m}^{2}$ \\
\hline \multirow[t]{2}{*}{2} & \multirow[t]{2}{*}{ Cơ lực } & Lực bóp tay (HS) & $26 \mathrm{~kg}$ & $18 \mathrm{~kg}$ \\
\hline & & Phản xạ xương bánh chè & $18 \mathrm{~kg}$ & $16 \mathrm{~kg}$ \\
\hline 3 & Tốc độ đi bộ & Đi bộ $6 \mathrm{~m}$ & $0,8 \mathrm{~m} / \mathrm{s}$ & $0,8 \mathrm{~m} / \mathrm{s}$ \\
\hline
\end{tabular}

Chuẩn đoán mất co khi có tiêu chuẩn (1) + (2) hoặc tiêu chuẩn (1) + (3) hoặc tiêu chuẩn (1) $+(2)+(3)$.

Bảng 2.2. Chuẩn đoán giai đoạn mất cơ theo hiệp hội mất cơ Châu Âu [5]

\begin{tabular}{|l|c|c|c|}
\hline \multicolumn{1}{|c|}{ Giai đoạn } & Khối lượng co & Co lực & $\begin{array}{c}\text { Hoạt động } \\
\text { thề chất }\end{array}$ \\
\hline Tiền mất cơ & Giảm & Bình thường & Bình thường \\
\hline Mất cơ & Giảm & Giảm & Hoặc giảm \\
\hline Mất cơ nặng & Giảm & Giảm & Giảm \\
\hline
\end{tabular}

2.2.5. Các tiêu chuẩn sử dụng trong nghiên cúu

- Đánh giá BMI cho người châu Á - Thái Bình Dương

- Phân loại huyết áp theo ESH/ESC 2007

- Mục tiêu kiểm soát Glucose máu của ADA 2014

- Mục tiêu kiểm soát lipid máu theo NCEP - ATP III

- Các tiêu chuẩn cho đánh giá tình trạng mất cơ theo theo hiệp hội mất cơ Châu Á.

\subsubsection{Xủ lý và phân tích số liệu}

Sử dụng phần mềm SPSS18.0 để xử lý số liệu.

- Mức giá trị xác xuất $\mathrm{p}<0,05$ được coi là có ý nghĩa thống kê

- Giá trị trung bình được biểu diễn dưới dạng $\mathrm{X} \pm \mathrm{SD}$.

\section{KẾT QUẢ NGHIÊN CÚU}

Qua nghiên cứu 56 bệnh nhân ĐTĐ típ 2 bao gồm (53,6\% tiền mất cơ, 33,9\% mất cơ vừa và $12,9 \%$ mất cơ nặng) độ tuổi trung bình $64,8 \pm 2,9$ tuổi tham gia tập luyện trong 12 tháng, chúng tôi thu được kết quả như sau

\subsection{Sự thay đổi về lâm sàng, cận lâm sàng của nhóm ĐTĐ trước tập và sau tập}

Bảng 3.1. Đặc điểm vể các chỉ số lâm sàng và cận lâm sàng trước và sau tập

\begin{tabular}{|c|c|c|c|}
\hline Đặc điểm & Trước & Sau & $\mathbf{p}$ \\
\hline Tuổi TB & \multicolumn{2}{|c|}{$64,8 \pm 2,9$} & \\
\hline Nam/nữ & \multicolumn{2}{|c|}{$18 / 38$} & \\
\hline
\end{tabular}




\begin{tabular}{|l|c|c|c|}
\hline Cân nặng $(\mathrm{kg})$ & $55,29 \pm 6,71$ & $55,79 \pm 6,65$ & $>0,05$ \\
\hline BMI $\left(\mathrm{kg} / \mathrm{m}^{2}\right)$ & $22,68 \pm 1,65$ & $22,99 \pm 1,79$ & $>0,05$ \\
\hline Huyết áp TTh & $139,1 \pm 7,7$ & $131,5 \pm 8,3$ & $<0,01$ \\
\hline Huyết áp TTr & $87,2 \pm 3,3$ & $81,2 \pm 5,2$ & $<0,01$ \\
\hline Glucose $(\mathrm{mmol} / \mathrm{l})$ & $8,42 \pm 2,26$ & $7,56 \pm 1,18$ & $<0,05$ \\
\hline HbA1C $(\%)$ & $7,98 \pm 1,28$ & $7,16 \pm 0,50$ & $<0,01$ \\
\hline Triglycerit $(\mathrm{mmol} / \mathrm{l})$ & $1,77 \pm 0,75$ & $1,45 \pm 0,71$ & $<0,05$ \\
\hline Cholesterol(mmol/1) & $5,04 \pm 1,14$ & $4,54 \pm 1,22$ & $<0,05$ \\
\hline LDL-C $(\mathrm{mmol} / \mathrm{l})$ & $2,89 \pm 0,89$ & $2,24 \pm 0,85$ & $<0,05$ \\
\hline HDL-C $(\mathrm{mmol} / \mathrm{l})$ & $1,34 \pm 0,65$ & $1,54 \pm 0,34$ & $<0,05$ \\
\hline
\end{tabular}

Nhận xét: Các chỉ số cân nặng, glucose, HbA1C, LDL-C và huyết áp giảm có ý nghĩa thống kê sau khi tập luyện so với trước tập với $\mathrm{p}<0,05-0,01$. Chỉ số HDL-C tăng lên trước so với sau tập với $\mathrm{p}<0,05$. BMI có xu hướng tăng lên nhưng sự khác biệt không có ý nghĩa thống kê với $\mathrm{p}>$ 0,05 .

\subsection{Sự thay đổi về các thành tố mất cơ của nhóm ĐTĐ trước và sau tập}

Bảng 3.2. Đặc điểm $\mathrm{ASMI}_{\mathrm{H}}$ của bệnh nhân, trước và sau tập theo phân loại mất cơ

\begin{tabular}{|c|c|c|c|c|}
\hline $\begin{array}{c}\text { Phân loại } \\
\text { mất co }\end{array}$ & Số BN & $\begin{array}{c}\text { ASMI } \\
\text { trước tập }\end{array}$ & $\begin{array}{c}\text { ASMI } \\
\text { sau tập }\end{array}$ & p \\
\hline Tiền mất cơ & $\begin{array}{c}30 \mathrm{BN}(53,6 \%) \\
12 \mathrm{Nam} / 18 \mathrm{Nu \tilde { }}\end{array}$ & $5,46 \pm 0,76$ & $5,57 \pm 0,73$ & $<0,05$ \\
\hline Mất cơ vừa & $\begin{array}{c}19 \mathrm{BN}(33,9 \%) \\
5 \mathrm{Nam} / 14 \mathrm{Nư}\end{array}$ & $5,31 \pm 0,70$ & $5,40 \pm 0,65$ & $>0,05$ \\
\hline Mất cơ nặng & $\begin{array}{c}7 \mathrm{BN}(12,5 \%) \\
1 \mathrm{Nam} / 6 \mathrm{Nữ}\end{array}$ & $4,68 \pm 0,98$ & $4,78 \pm 0,98$ & $>0,05$ \\
\hline Tổng & $\begin{array}{c}56 \mathrm{BN}(100,0 \%) \\
18 \mathrm{Nam} / 38 \mathrm{Nư}\end{array}$ & $5,31 \pm 0,79$ & $5,41 \pm 0,76$ & $<0,05$ \\
\hline
\end{tabular}

Nhận xét: Chỉ số $\mathrm{ASMI}_{\mathbf{H}}$ cải thiện sau tập ở cả ba nhóm tiền mất cơ, mất cơ vừa và mất cơ nặng nhưng chỉ có ý nghĩa thống kê với $\mathrm{p}<0,05$ ở nhóm tiền mất cơNhóm mất cơ vừavà nhóm mất cơ nặng thì mặc dù $\mathrm{ASMI}_{\mathbf{H}}$ có xu hướng tăng lên nhưng sự khác biệt lại chưa có ý nghĩa thống kê với $\mathrm{p}>0,05$.

\begin{tabular}{|c|c|c|c|}
\hline \multicolumn{1}{|c|}{ Bảng 3.3. Tốc độ đi bộ trước và sau tập theo giới } \\
\hline $\begin{array}{c}\text { Tộ đi bộ } \\
(\mathbf{m} / \mathbf{s})\end{array}$ & Trước & Sau & $\mathbf{p}$ \\
\hline Nam & $0,72 \pm 0,18$ & $0,82 \pm 0,18$ & $<0,05$ \\
\hline Nữ & $0,62 \pm 0,14$ & $0,69 \pm 0,17$ & $<0,05$ \\
\hline Tổng & $0,65 \pm 0,16$ & $0,73 \pm 0,18$ & $<0,05$ \\
\hline
\end{tabular}

Nhận xét: Tốc độ đi bộ của nhóm ĐTĐ có xu hướng cải thiện và có xu hướng cải thiện hơn ở nữ. Sự khác biệt có ý nghĩa thống kê với $\mathrm{p}<0,05$ ở cả hai giới.

Bảng 3.4. Cơ lực trước và sau tập theo giới

\begin{tabular}{|c|c|c|c|}
\hline Co lực tay (kg) & Trước & Sau & p \\
\hline Nam & $30,6 \pm 10,1$ & $34,4 \pm 11,5$ & $<0,05$ \\
\hline Nữ & $14,1 \pm 10,7$ & $17,5 \pm 10,5$ & $<0,05$ \\
\hline Tổng & $19,4 \pm 14,4$ & $22,9 \pm 14,0$ & $<0,05$ \\
\hline
\end{tabular}

Nhận xét: Cơ lực của bệnh nhân cải thiện sau tập có ý nghĩa thống kê với $\mathrm{p}<0,05$ ở cả nam và nữ 


\section{BÀN LUẬN}

Khối cơ là cơ quan nội tiết lớn nhất trong cơ thể và là nơi hấp thu $80 \%$ glucose máu sau ăn. Mất cơ làm giảm hấp thu glucose máu, làm cho kiểm soát glucose máu kém hơn và gia tăng các biến chứng. Ngược lại, trong bệnh sinh của ĐTĐ típ 2 đề kháng insulin, các sản phẩm chuyển hóa cuối của glucose (AGE), gia tăng các yếu tố viêm thúc đẩy qúa trình mất cơ nhanh hơn. Chính vì vậy, mất cơ và ĐTĐ là hai quá trình diễn ra song song, tác động qua lại làm trầm trọng lẫn nhau [6]. Nhiều nghiên cứu cho thấy tập luyện làm giảm glucose máu, quá trình viêm làm cải thiện khối cơ và vận động, làm chậm tiến trình mất cơ [7], [8], [9].

Theo nghiên cứu của chúng tôi, trên 56 bệnh nhân ĐTĐ típ 2 cho thấy khối cơ đã được cải thiện ở thời điểm sau tập so với thời điểm trước khi tập 12 tháng. Chỉ số $\mathrm{ASMI}_{\mathrm{H}}$ cải thiện sau tập ở cả ba nhóm tiền mất cơ, mất cơ vừa và mất cơ nặng nhưng chỉ có ý nghĩa thống kê với $\mathrm{p}<0,05$ với nhóm tiền mất cơ. Riêng nhóm mất cơ vừa và mất cơ nặng thì mặc dù $\mathrm{ASMI}_{H}$ có xu hướng tăng lên nhưng sự khác biệt lại chưa có ý nghĩa thống kê với $\mathrm{p}>0,05$.

Có thể lý giải như sau: bệnh nhân tiền mất cơ vì chưa có giảm về chất lượng cơ như tốc độ đi bộ, cơ lực tay nên khả năng tuân thủ bài tập tốt hơn, tham gia các hoạt động hàng ngày nhiều hơn khi có sự tư vấn của bác sĩ. Vì vậy, mức độ cải thiện về khối cơ sau 12 tháng tập luyện có ý nghĩa thống kê. Tuy nhiên sau khi tập, các bệnh nhân đều có có sự thay đổi về khối cơ nhưng có cải thiện hơn về cơ lực tay và tốc độ đi bộ có thể thói quen tập luyện đã làm tăng sức bền, cải thiện tình trạng viêm, glucose máu, huyết áp giúp làm tăng cơ lực. Các nghiên cứu đều chỉ ra rằng tập luyện đối kháng giúp tăng khối cơ chỉ trong thời gian ngắn và cường độ cao, có máy hỗ trợ và có sự hướng dẫn của chuyên gia. Tuy nhiên trong nghiên cứu của chúng tôi, cường độ không cao và thời gian cũng không quá dài nhưng cũng cho thấy những hiệu quả rõ rệt. Mặc dù mất cơ và tiền mất cơ được nhận ra là tiềm ẩn những nguy cơ lớn đối với người cao tuổi nhưng cho đến gần đây có rất ít chương trình được triển khai nhằm cải thiện tình trạng này. Nghiên cứu này của chúng tôi là một trong những nghiên cứu bước đầu đánh giá về tác dụng tập luyện đối kháng đối với mất cơ và tiền mất cơ vì có nhiều bằng chứng cho thấy rằng tập luyện đối kháng cải thiện tình trạng giảm mất cơ và tiền mất cơ ở người cao tuổi. Người cao tuổi thường ít vận động dẫn đến giảm khối lượng cơ và cơ lực. Những phát hiện về bản chất này sẽ giúp các nhà khoa học và các bác sĩ lâm sàng có bằng chứng khoa học khi quyết định sử dụng tập luyện đối kháng để điều trị, làm chậm và/ hoặc ngăn ngừa mất cơ giảm và tiền mất cơ. Một lần nữa khẳng định tập luyện đối kháng có vai trò rất quan trọng trọng việc ngăn ngừa mất cơ do kích thích làm tăng nhạy cảm insullin, cải thiện glucose máu tốt hơn, giảm các stress oxy hóa làm tăng khối cơ và cơ lực bằng cách tăng tổng hợp và giảm thoái hoá protein trong khối cơ. Theo Heo JW (2017) tập luyện đối kháng làm tăng thiết diện trong mặt cắt ngang sợi cơ, đặc biệt tăng sợi co cơ nhanh (sợi loại II) hơn sợi co cơ chậm (sợi loại I) [10]. Do vậy, tập luyện đối kháng làm tăng cả khối lượng và chất lượng cơ.

Sau 12 tháng tập luyện thì tốc độ đi bộ cải thiện ở nam với chỉ số trước tập là $0,72 \pm 0,18$ $\mathrm{m} / \mathrm{s}$ và sau tập là $0,82 \pm 0,18 \mathrm{~m} / \mathrm{s}$ với $\mathrm{p}<0,05$. Ở nữ thì tốc độ đi bộ là $0,69 \pm 0,17 \mathrm{~m} / \mathrm{s}$ nhanh hơn trước tập là $0,62 \pm 0,14 \mathrm{~m} / \mathrm{s}$ với $\mathrm{p}<0,05$. Điều này có thể giải thích được sau 12 tháng tập luyện thì khối cơ chân tăng ở cả nam và nữ giúp cải thiện tốc độ đi bộ. Về cơ lực tay thì sự cải thiện ở nam là $34,4 \pm 12,5 \mathrm{~kg}$ cao hơn so với trước tập là $30,6 \pm 11,0$ kg,ở nữ là 17,5 $\pm 10,5 \mathrm{~kg}$ cao hơn so với trước tập là $14,1 \pm$ 11,7 kgvới $\mathrm{p}<0,05$. Sự thay đồi này có ý nghĩa thống kê $(\mathrm{p}<0,05)$.

\section{KẾT LUẬN}

Theo dõi sau tập 12 tháng tập trên 56 bệnh nhân ĐTĐ típ 2 bao gồm 30 bệnh nhân tiền mất cơ, 19 bệnh nhân mất cơ vừa và 7 bệnh nhân mất cơ nặng có cải thiện về chỉ số khối cơ sau tập tăng hơn trước tập, nhưng chỉ có nhóm tiền mất cơ là khác biệt có ý nghĩa thống kê với $\mathrm{p}<0,05$.

Cải thiện về $\mathrm{ASMI}_{\mathrm{H}}$ ở nhóm tiền mất cơ, mất cơ vừa và mất cơ nặng lần lượt trước và sau tập là $\left(5,46 \pm 0,76 \mathrm{~kg} / \mathrm{m}^{2} ; 5,57 \pm 0,73 \mathrm{~kg} / \mathrm{m}^{2}\right), \mathrm{p}$ $<0,01 ;\left(5,31 \pm 0,70 \mathrm{~kg} / \mathrm{m}^{2} ; 5,40 \pm 0,65 \mathrm{~kg} / \mathrm{m}^{2}\right)$, 
$\mathrm{p}>0,05 ;\left(4,68 \pm 0,98 \mathrm{~kg} / \mathrm{m}^{2} ; 4,78 \pm 0,98 \mathrm{~kg} / \mathrm{m}^{2}\right)$, $\mathrm{p}>0,05$. Tốc độ đi bộ ở giới nam $0,72 \pm 0,18 \mathrm{~m} / \mathrm{s}$ và $0,82 \pm 0,18 \mathrm{~m} / \mathrm{s}$, ở nữ là $0,62 \pm 0,14 \mathrm{~m} / \mathrm{s}$ và $0,69 \pm 0,17 \mathrm{~m} / \mathrm{s}$ với $\mathrm{p}<0,05$. Cơ lực tay giới nam là $30,6 \pm 11,0 \mathrm{~kg}$ và $34,4 \pm 12,5 \mathrm{~kg}$; ̛̛̉ nữ là 14,1 $\pm 11,7 \mathrm{~kg}$ và $17,5 \pm 104,5 \mathrm{~kg}$ với $\mathrm{p}<0,05$.

\section{KHUYẾN NGHI}

Cần sàng lọc tiền mất cơ sớm cho bệnh nhân ĐTĐ típ2 và tư vấn bài tập phù hợp để ngăn chặn diễn tiến mất cơ nâng cao chất lượng sống cho người bệnh.

\section{TÀI LIỆU THAM KHẢO}

1. Rosenberg IH (1997). Sarcopenia: origins and clinical relevance. J Nutr, 127(5 Suppl), 990S-991S.

2. Schwartz A.V, Hillier T.A, Sellmeyer D.E et al (2002). Older women with diabetes have a higher risk of falls: a prospective study. Diabetes Care, 25(10), 1749-1754.

3. Tanimoto Y, Watanabe M, Sun W et al (2013). Association of sarcopenia with functional decline in community-dwelling elderly subjects in Japan. Geriatr Gerontol Int, 13(4), 958-963.

4. Chen L.K, Liu L.K, Woo J et al (2014). Sarcopenia in Asia: consensus report of the Asian Working Group for Sarcopenia. J Am Med Dir Assoc, 15(2), 95-101.

5. Cruz-Jentoft A.J, Baeyens J.P, Bauer J.M et al (2010). Sarcopenia: European consensus on definition and diagnosis:
Report of the European Working Group on Sarcopenia in Older People. Age Ageing, 39(4), 412-423.

6. Mesinovic J, Zengin A, De Courten B et al (2019). Sarcopenia and típe 2 diabetes mellitus: a bidirectional relationship. Diabetes Metab Syndr Obes, 12, 10571072.

7. Peterson M.D, Sen A, Gordon P.M (2011). Influence of resistance exercise on lean body mass in aging adults: a metaanalysis. Med Sci Sports Exerc, 43(2), 249-258.

8. Dunstan D.W, Daly R.M, Owen N et al (2002). High-intensity resistance training improves glycemic control in older patients with típe 2 diabetes. Diabetes Care, 25(10), 1729-1736.

9. Geirsdottir O.G, Arnarson A, Briem K et al (2012 ). Effect of 12-Week Resistance Exercise Program on Body Composition, Muscle Strength, Physical Function, and Glucose Metabolism in Healthy, InsulinResistant, and Diabetic Elderly Icelanders. Journal of Gereoronntotolologgy, 67(11), 12591265.

10. Jun W.H, Mi H.N, Dong H.M et al (2017). Aging-induced Sarcopenia and Exercise. The Official Journal of the Korean Academy of Kinesiology, 19(2), 43-59. 